\title{
Performance of Rotational Speed Controlled Small-Scale Head-Dependent Hydroelectric Power Plant
}

\author{
Tuomo Lindh, Risto Tiainen, Jero Ahola, Markku Niemelä, Ville Särkimäki \\ Lappeenranta University of Technology, \\ P.O. Box 20, FIN-53851 Lappeenranta, Finland \\ E-mail: tuomo.lindh@lut.fi
}

\begin{abstract}
Small scale or micro scale hydroelectric power production is characterized by high investment costs compared to operation costs. In addition, the repayment time is often long, more than ten years (if not subsidized heavily) which requires that a small-scale hydropower plants can be profitable only if both the investment costs and the running costs are low. The performance and efficiency of a plant is very important because having long repayment time means that the efficiency improvement of one percentage unit often means the ten percentage unit improvement in profit. The most economical way to control the flow is sometimes a two point control where generators are switched on and off depending on high water level used as control variable. The water level cannot be kept constant using this method, but the traditionally used mechanical blade angle adjustment system is too expensive in very small (approximately $<100 \mathrm{~kW}$ ) units. The new method of controlling the upper water level (head) is the use of rotational speed control of turbine, implemented by a four quadrant frequency converter. The efficiency of a 4-quadrant frequency converter is approximately $97 \%$, which reduces the income compared to the situation where the generators are directly connected to electricity network. However, when the head is kept constant using a frequency converter, it is not required to switch off the generator circuit breakers which have a finite life time and the head height can be kept optimal in terms of performance. In this paper, a system structure, a pilot plant installation and example calculations on the feasibility of a frequency converter driven fixed blade hydro power turbine is given.
\end{abstract}

Index Terms-Distributed generation, Fixed blade turbine, Hydroelectric power generation, head dependent, 4-quadrant frequency converter

\section{INTRODUCTION}

THE Frequency converters can be utilized in a hydropower plant as a control method alternative to using a variable blade angle turbine or a bank of fixed blade angle turbines that can be utilized in different combinations to have the head change as little as possible (two-point control). The overall economical feasibility of the options will be determined by their investment and operating (maintenance) costs, and efficiency. The feasibility of the rotational speed control method is studied and compared to two point control in this paper. The fixed blade turbine efficiency is reduced greatly when the rotational speed is changing from its nominal point (approximately $10 \%$ per every $20 \%$ change from nominal rotational speed according to the measurements made in our Pilot installation), (This will be presented in a final paper). The performance of variable blade angle turbines remains at high level with a wide flow range [1], but the investment cost is higher than the rotational speed control when very small turbines are used $(<100-200 \mathrm{~kW})$. In addition, the use of frequency converter makes it possible to utilize commercially available PM-generators, which have much higher efficiency than the asynchronous generators.

\section{Pilot Installation}

The pilot power station is situated in Tirva, a small village near Lappeenranta in South-Eastern Finland. The pilot plant consists of four turbogenerator units. All units are equipped with fixed blade turbines. Four of the generators are directly grid connected, and one is driven by a four-quadrant frequency converter. The frequency range of the variable speed generator is 0.6-1.2 times the nominal frequency (50 $\mathrm{Hz}$ ). The nominal power of the variable speed generator is 50 $\mathrm{kW}$. For a nominal head this turbine gives $30-60 \mathrm{~kW}$ using the full frequency range. The nominal powers of the other generators are $20 \mathrm{~kW}, 30 \mathrm{~kW}$, and $100 \mathrm{~kW}$. The power is controlled by switching the generators on and off, and controlling the frequency of the converter-driven generator. In this research, the efficiencies of generators are assumed equal. The losses of the frequency converter are taken into account as a reduced income. The $50 \mathrm{~kW}$ asynchronous generator was replaced by PM-generator which in turn increased the efficiency by almost two percentage units. Then total efficiency of frequency converter drive is reduced only by approximately one percentage unit. The breaking (switching off) cost of the circuit breaker is calculated from the replacement cost of the breaker. 


\section{EXAMPLE CALCULATION}

In order to evaluate the performance of a rotational speed control, a model of the power plant were implemented in Matlab $^{\circledR}$. The inflow was assumed to be constant over the evaluation time window $(24 \mathrm{~h})$. The usage of the two-point control and the frequency converter in keeping the head constant are illustrated in Fig. 1 and Fig. 2. In the upper diagram is presented the hourly changing energy price $[2,3]$. In the middle diagram, the total power of plant is presented hour by hour and the in the lower diagram illustrates the head height for corresponding hour. The income is calculated hourly based. The shape of the price curve does not remarkably affect the difference between the incomes of frequency converter control and two point control.
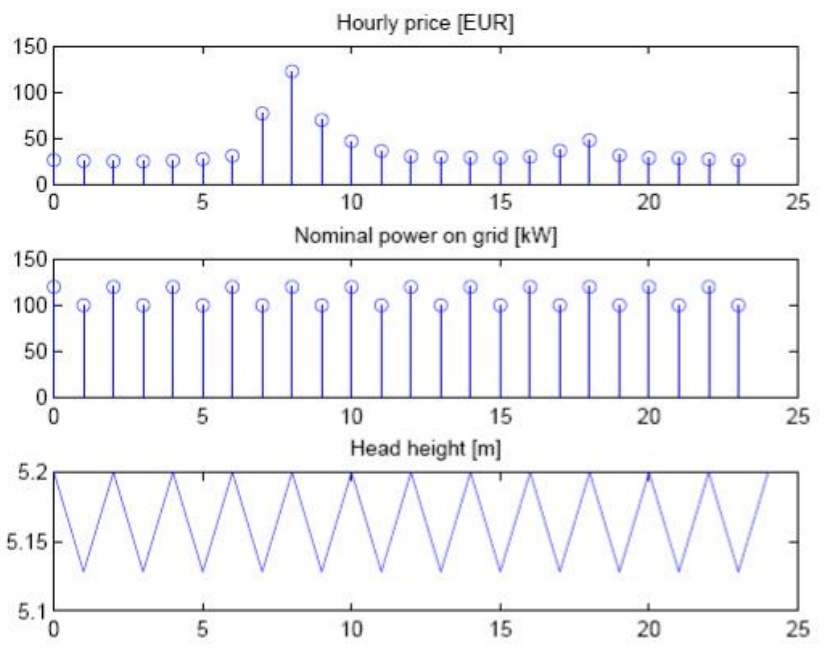

Fig. 1. Two-point control. The head is kept as constant as possible by the use of two generator combinations providing $100 \mathrm{~kW}$ and $120 \mathrm{~kW}$.
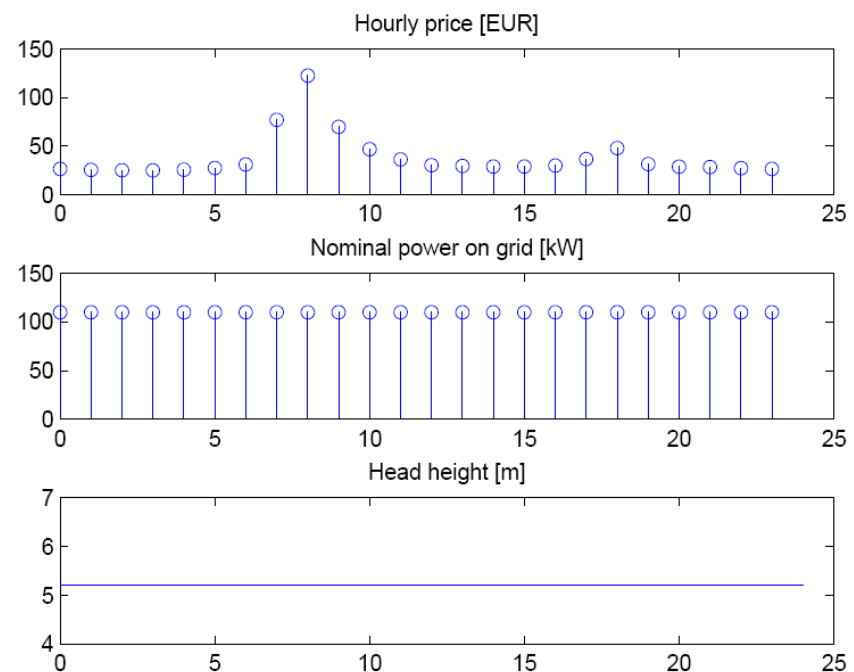

Fig. 2. Head control using a frequency converter. The power can be kept at constant $110 \mathrm{~kW}$. Compared to the two-point control (Fig. 1), switching of generator circuit breakers is eliminated, and the head is not fluctuating.
The flow is constant corresponding to a power of $110 \mathrm{~kW}$ which is produced by $20 \mathrm{~kW}, 30 \mathrm{~kW}$ and the frequency converter driven $50 \mathrm{~kW}$ generator running with $20 \%$ over its nominal power. The above simulation example results to the increase of income from $107 € /$ day to $117 € /$ day. The calculation does not take into account the efficiency reduction due to the frequency converter and the non-nominal rotational speed of the turbine. This is calculated separately. In the above case, the efficiency of a frequency converter is $97 \%$ [4] and the efficiency of fixed blade turbine is reduced $10 \%$ with the $20 \%$ rotational speed change from the nominal. Therefore, the total calculated income is reduced by $6 \%$, resulting to the final income of $109.5 €$. The income is still slightly higher than without the frequency converter. Then, if the PM-machine is used with the frequency converter, the reduction of income is $4 \%$ and the final income is $112 €$. When a four quadrant frequency converter of this size costs more than $6000 €$ and the PM-generator is ca. $50 \%$ more expensive than the asynchronous generator, the repayment time of the frequency converter is at least four years. On the other hand, if the mechanical blade angle control costs more than $30000 €$, even with its performance superiority the repayment time can be doubled compared to the rotational speed control. This is only valid when the generator size is less than ca. 100-200 kW, because the frequency converter price increases almost linearly with power whereas the cost of the mechanical blade angle control increases slower with power.

\section{CONCLUSIONS}

The frequency converter can be used for the head adjustment. However, the poor efficiency of fixed blade turbine outside of the nominal rotational speed restricts the rotational speed range. When the frequency converter is used, the design of the blade should be designed so that the efficiency curve is flat and not optimized for nominal rotational speed. Compared to the two-point control, the rotational speed control guarantees unchanged upper water level which is often required. This kind of control can be added to existing power plants also whereas mechanical angle control is not feasible to install.

\section{REFERENCES}

[1] J. M. Blanco Barrero, P. Lara Santillán, J. C. Sáenz-Díez Muro, E. Jiménez Macías, "Optimization of hydrological utilization for hydroelectric power plants of flowing type", International conference on renewable energies and power quality (ICREPQ'07), Sevilla, 2007.

[2] O. Gjerde, "The Deregulated Nordic Electricity Market - 10 Years of Experience," Proceedings of the Transmission and Distribution Conference and Exhibition, Vol. 2. Yokohama, Japan, 6-10 Oct. 2002.

[3] Nord Pool Spot WWW Page, http://www.nordpoolspot.com. Accessed Sep 152007.

[4] ACS800_Catalogue_REV_E_171003.pdf. Available at http://www.abb.fi WWW Page. 